\title{
Research on the Relation between Strength Quality and Body Fat Ratio of College Students
}

\author{
Zhennan ZHU \& Ling CAO \\ Physical Education Department, Dalian University of Technology, Dalian, Liaoning
}

\begin{abstract}
The obesity and decrease in strength quality become a more and more serious problem among college students. In order to research the relation between the strength quality of college students and the body fat ratio, to discuss the effects of obesity status on the strength quality, to provide a reference for the individual strength quality lifting scheme, 300 new students in a certain university were randomly selected for the measurements of height, weight, and body composition. The index tests of the grip strength, standing long jump as well as push-ups (sit-ups) were also carried out for the selected objects. The results indicate that the muscle strength of girls is significantly lower than that of boys, and the body fat ratio of girls is higher than that of boys. It is also found that the body fat has bad effect on the leg strength of boys but has negative influence on limb strength of girls.
\end{abstract}

KEYWORD: Strength Quality; Body Fat Rates; Obesity factor; College Students

Chinese teenagers' physical quality including strength, speed, explosive force and stamina has been worse and worse for many years. The data of national physique monitoring show that Chinese teenagers have wider chest but smaller lung capacity; they are taller but run more slowly; they gain more weight but less strength[1]. The data of recent years college students' physical fitness test also tell us that there is a dropping tendency on the college students physique year after year[2]. Under the educational guideline of "Health First", the issue how to improve students' physical quality through scientific and reasonable training plans has been one of the problems which are badly in need of solution in the current college sports education.

In all indexes reflecting the physique, the strength quality is the basis of mastering motor skills and supporting other physical fitness[3]. Our work is to analyze the test results of strength quality and body composition of college students so as to give advice on the targeted training plans of improving college students' physical quality and provide a reference for making scientific college sports work plans.

\section{OBJECTS AND METHODS}

\subsection{Research objects}

Consider the 300 new college students selected by random cluster sampling in a certain university as the test objects of this study. There are 160 boys aging from 18-23 years old and with the average age of 19.8 ( $\mathrm{SD}=0.9$ )years old; the other 140 students is girls whose age is from 18-23 years old and average age is $19.8(\mathrm{SD}=0.9)$ years old.

\subsection{Research methods}

\subsubsection{Literature analysis methods}

Look up and collect relative data, and investigate the data using the literature analysis method.

\subsubsection{Measurements}

\subsubsection{Strength quality test}

The test indexes include grip strength, standing long jump as well as push-ups by males/sit-ups by females. The test should be performed according to the fitness testing standards set by General Administration of Sport of China.

\subsubsection{Body composition tests}

Test the body composition by bioelectrical impedance analysis and use Japanese TBF-418B body composition analyzer as the test instrument. The test methods are: 1) to measure the height using a height/weight tester; 2) to let the subject stand barefoot on the foot electrodes with light sports clothing; 3) to keep the subject griping the hand electrodes and stay still; 4)to transmit the test results to the computer and to be processed. The test 
indexes includes weight, body mass index, protein, minerals, moisture and the body fat content, fat-free content, muscle content and body fat ratio of the whole body, the upper and lower limbs and all parts of the body.

\subsection{The indexes and standards of body fat ratio}

The body fat ratio which has the highest correlation with body fat content is the best standard to diagnose the obesity indirectly. Generally, if the body fat ratio of males is more than $25.0 \%$ and of females is more than $30.0 \%$, they will be diagnosed as obesity[4].

\subsection{Statistical analysis}

Process the data by statistical software IBM SPSS Statistics 19. The obtained data is presented in the way of $\mathrm{M} \pm \mathrm{SD}$ and percentage. And we adopt the independent sample t test to compare the mean of all indexes. $\mathrm{P}<0.05$ is the significance level in statistics.

\section{RESULTS AND DISCUSSIONS}

\subsection{Basic characteristics of the object of study}

As shown in Table 1, dividing the body composition of the subjects by their weight to eliminate the effects of weight, we can get the ratios of all the body composition to weight including body fat content, fat-free content, moisture, muscle content, protein and minerals. The data show that there is a significant difference $(\mathrm{p}<0.05)$ in the ratios of all the body composition to weight. In addition, the body fat ratio of girls which arrives(31.5 \pm 3.8$) \%$ is higher than boys' $(16.2 \pm 5.2) \%$. While the rate of muscle to weight of girls is obviously lower than boys', the rate of body fat content to weight of girls is higher than boys' obviously $(\mathrm{p}<0.05)$.

The body fat rate can scientifically stand for the degree of human body fatness[5]. The fat is an important component of the human body. The appropriate fat content and component ratio are the structural and material basis for normal human's life. The study finds that there is an obvious difference in fat content and component ratio between two sexes after puberty but little difference before puberty[6-8]. The sex differences in subjects' body composition shown in Table 1 are in accordance with previous research conclusions. There are many reasons why the body composition of the subjects, especially the body fat ratio, are different between two sexes[9]. Moreover, the androgen, one of important hormones compounding protein, can increase the amount of protein in muscle and improve muscle quality and the estrogen causes the accumulation of subcutaneous fat to increase continually. At last, female college students dieting, taking weight-loss pills and hating sports activities also influence the results of the study.

Table 1. Basic information of research objects

\begin{tabular}{|c|c|c|}
\hline & Boys $(n=160)$ & $\operatorname{Girls}(n=140)$ \\
\hline & $\mathrm{cm}$ inches & $\mathrm{cm}$ inches \\
\hline Age(years old) & $19.8 \pm 0.9$ & $19.3 \pm 1.3$ \\
\hline Height $(\mathrm{cm})$ & $174.1 \pm 6.3$ & $160.0 \pm 3.7$ \\
\hline Weight $(\mathrm{kg})$ & $66.5 \pm 12.5$ & $57.2 \pm 7.7$ \\
\hline Body mass index $\left(\mathrm{kg} / \mathrm{cm}^{2}\right)$ & $21.9 \pm 3.2$ & $22.3 \pm 2.2$ \\
\hline Body fat ratio(\%) & $16.2 \pm 5.2 * *$ & $31.5 \pm 3.8$ \\
\hline Body fat content/weight & $0.17 \pm 0.05^{*}$ & $0.31 \pm 0.04$ \\
\hline Fat-free content/weight & $0.83 \pm 0.05$ & $0.69 \pm 0.04 * *$ \\
\hline Moisture /weight & $0.56 \pm 0.05$ & $0.47 \pm 0.02 * *$ \\
\hline Muscle /weight & $0.80 \pm 0.05$ & $0.65 \pm 0.03 * *$ \\
\hline Protein/weight & $0.24 \pm 0.01$ & $0.18 \pm 0.02 * *$ \\
\hline Minerals/weight & $0.043 \pm 0.00$ & $0.039 \pm 0.00 *$ \\
\hline
\end{tabular}

$* \mathrm{p}<0.05, * * \mathrm{p}<0.001$

\subsection{Strength quality}

The test results of strength quality of the subjects are shown in Table 2. Grip strength, mainly reflecting the strength of forearms and hand muscles[10], is different among boys and girls. The results of boys and girls are $0.7 \pm 0.2$ and $0.5 \pm 0.1$ after dividing the weight. The boys' and girls' scores of standing long jump that tests lower limbs strength and outbreak ability of are $2.2 \pm 0.2$ meters and $1.7 \pm 0.2$ meters respectively. Push-ups reflect the strength of upper limbs and shoulder-back muscle group and the ability for muscle to continue working. Sit-ups reflect the strength of the endurance. The numbers of boys' push-ups and girls' sit-ups are 29.1 \pm 12.7 times and $29.4 \pm 10.5$ times in a minute.

\subsection{Relation between the strength quality and the body fat ratio}

In the study, the number of students who is judged as obesity (body fat percentage $>25 \%$ ) by the use of the body fat rate is 79 , including 9 boys and 70 girls and they respectively occupy $3 \%$ and $23.3 \%$ of the total (according to the Table 3). The schoolboys, whose whole body fat rate is above 25 , the various index of the physical is the power of gripping/weight is $0.6 \pm 0.2$, the test value of the standing long jump is $1.8 \pm 0.3$ meters, the time of push-ups is $19 \pm 11.3$. And the partial fat rate respectively is upper $\operatorname{limb} 24.5 \pm 3.2 、 24.1 \pm 3.3$, and the lower limb is $26.7 \pm 4.8 、 26.7 \pm 4.1$, and the trunk is $28.8 \pm 4.7$. And the schoolboys, whose body fat percentage is under 25 , the test value of various index of the power of gripping/weight, standing long jump and push-up respectively is $0.7 \pm 0.1,2.3 \pm 0.2$ meters, $30 \pm 12.7$ times. The body fat percentage of upper limb is $14.3 \pm 2.9,14.9 \pm 2.9$, and the body fat rate of lower limb is $26.7 \pm 4.8,26.7 \pm 4.1$ and the body fat rate of the trunk is $14.7 \pm 5.1$. The schoolboys who are obese 
differ a lot from the boys whose body fat rate is normal in terms of the test performances of standing long jump $(\mathrm{p}<0.05)$. Though the results of the power of gripping/weight, push-up differs a little, they don't have the statistics significance $(p>0.05)$; as for boys, besides the upper limbs, the body fat rate of the lower limb and the trunk are all above the standards, in addition, the boys who is obese differs a lot from the boys whose body fat rate is normal in the terms of the lower limb and the trunk $(\mathrm{P}<0.05)$.

The girls, whose body fat rate is above 30 , the power of gripping/weight of them is $0.4 \pm 0.1$, the test value of standing long jump is $1.6 \pm 0.2$ meter, the time of push-up is $28 \pm 13.5$ times. However, the girls whose body fat rate is under 30 , the power of gripping/weight, the test value of standing long jump and the push-ups respectively is $0.6 \pm 0.1$, $1.8 \pm 0.1$ meter, $31 \pm 6.6$ times. The girl students who are obese differ a lot from those whose body fat rate is normal in terms of the power of gripping/weight and the standing long jump $(\mathrm{p}<0.05)$, but it differs a little on push-ups.(p>0.05) The girl students whose whole body fat rate is above 30 , the body fat rate of their left and right limbs and trunks respectively is $26.3 \pm 1.7,24.0 \pm 1.9,30.6 \pm 1.2,30.5 \pm 1.2,26.0 \pm 2.1$; in addition, besides the fat rate of upper limbs of the girl students whose body fat rate is above 30, the body fat rate of the upper and lower limbs and trunks is above the standard, and the girl students who are obese differs a lot from those whose body fat rate is normal in term of the body fat rate of upper limbs and the lower limbs. $(\mathrm{P}<0.05)$

Table 2. Strength quality of research objects.

\begin{tabular}{|c|c|c|}
\hline & Boys(n=160) & Girls(n=140) \\
\hline Grip strength/weight & $0.7 \pm 0.2$ & $0.5 \pm 0.1$ \\
\hline standing long jump(meters) & $2.2 \pm 0.2$ & $1.7 \pm 0.2$ \\
\hline Push-ups/Sit-ups(times) & $29.1 \pm 12.7$ & $29.4 \pm 10.5$ \\
\hline
\end{tabular}

When we use the method of body fat rate to judge the obesity, we can judge the overweight and those whose muscular isn't very strong but their appearance whose height and weight have a certain proportion and their body lipid content is higher correctly. Therefore, we can reflect the fatness degree of people objectively[11]. The muscle content of human usually reduces as the loss of weight.

Because the shape of human is very complicated, the cross sectional area of extremities and trunks differs a lot. So the whole body fat ratio has low precision in the application[12]. Therefore, the study analyzes the partial body fat ration from the whole body to the different parts, and then it analyzes the relation between the strength quality and the body fat ratio.
Table 3. The relation of Body fat ratio and strength quality

\begin{tabular}{|c|c|c|c|c|c|}
\hline & \multicolumn{2}{|c|}{ Boys } & \multicolumn{2}{|c|}{ Girls } \\
\hline & & $\begin{array}{c}\text { Body fat } \\
\text { ratio }>25 \\
(n=9)\end{array}$ & $\begin{array}{l}\text { Body fat } \\
\text { ratio } \leqq 25 \\
(n=151)\end{array}$ & $\begin{array}{c}\text { Body fat } \\
\text { ratio }>30 \\
(n=70)\end{array}$ & \begin{tabular}{|c|} 
Body fat \\
ratio $\leqq 30$ \\
$(n=70)$ \\
\end{tabular} \\
\hline \multicolumn{6}{|c|}{ Strength quality } \\
\hline \multicolumn{2}{|c|}{ Grip strength/weight } & $0.6 \pm 0.2$ & $0.7 \pm 0.1$ & $0.4 \pm 0.1$ & $0.6 \pm 0.1^{*}$ \\
\hline \multicolumn{2}{|c|}{$\begin{array}{l}\text { standing long } \\
\text { jump(meters) }\end{array}$} & $1.8 \pm 0.3$ & $2.3 \pm 0.2^{*}$ & $1.6 \pm 0.2$ & $1.8 \pm 0.1^{*}$ \\
\hline \multicolumn{2}{|c|}{$\begin{array}{c}\text { Push-ups/Sit- } \\
\text { ups(times) }\end{array}$} & $19 \pm 11.3$ & $30 \pm 12.7$ & $28 \pm 13.5$ & $31 \pm 6.6$ \\
\hline \multicolumn{6}{|c|}{ Body fat ratio } \\
\hline \multirow{2}{*}{$\begin{array}{l}\text { Right } \\
\text { upper } \\
\text { limbs }\end{array}$} & $\begin{array}{l}\text { Body fat } \\
\text { ratio }\end{array}$ & $24.5 \pm 3.2$ & $14.3 \pm 2.9$ & $32.1 \pm 2.0$ & $32.1 \pm 2.0$ \\
\hline & $\begin{array}{l}\text { cle } \\
\text { ent }\end{array}$ & $2.8 \pm 0.7$ & $2.5 \pm 0.3$ & $1.7 \pm 0.2$ & $1.5 \pm 0.2$ \\
\hline \multirow{2}{*}{$\begin{array}{l}\text { Left } \\
\text { upper } \\
\text { limbs }\end{array}$} & $\begin{array}{l}\text { Body fat } \\
\text { ratio }\end{array}$ & $24.1 \pm 3.3$ & $14.9 \pm 2.6$ & $33.0 \pm 2.0^{*}$ & $26.3 \pm 1.7$ \\
\hline & $\begin{array}{l}\text { Muscle } \\
\text { content }\end{array}$ & $2.7 \pm 0.8$ & $2.3 \pm 0.3$ & $1.7 \pm 0.1$ & $1.4 \pm 0.2$ \\
\hline \multirow{2}{*}{$\begin{array}{l}\text { Right } \\
\text { lower } \\
\text { limbs }\end{array}$} & $\begin{array}{l}\text { Body fat } \\
\text { ratio }\end{array}$ & $26.7 \pm 4.8^{*}$ & $16.4 \pm 3.2$ & $35.7 \pm 1.5^{*}$ & $30.5 \pm 1.2$ \\
\hline & $\begin{array}{l}\text { Muscle } \\
\text { content }\end{array}$ & $12.5 \pm 3.3$ & $9.4 \pm 1.4$ & $6.4 \pm 0.5$ & $5.9 \pm 0.5$ \\
\hline \multirow{2}{*}{$\begin{array}{l}\text { Left } \\
\text { lower } \\
\text { limbs }\end{array}$} & $\begin{array}{l}\text { Body fat } \\
\text { ratio }\end{array}$ & $26.7 \pm 4.1^{*}$ & $16.4 \pm 3.2$ & $35.4 \pm 1.5^{*}$ & $30.6 \pm 1.2$ \\
\hline & $\begin{array}{l}\text { Muscle } \\
\text { content }\end{array}$ & $12.3 \pm 3.5$ & $9.3 \pm 1.3$ & $6.4 \pm 0.5$ & $5.8 \pm 0.5$ \\
\hline \multirow{2}{*}{ Trunk } & $\begin{array}{l}\text { Body fat } \\
\text { ratio }\end{array}$ & $28.8 \pm 4.7$ & $28.8 \pm 4.7$ & $33.5 \pm 2.4$ & $30.0 \pm 2.1$ \\
\hline & $\begin{array}{l}\text { Muscle } \\
\text { content }\end{array}$ & $33.8 \pm 6.9$ & $28.1 \pm 2.4$ & $28.1 \pm 2.4$ & $20.0 \pm 1.9$ \\
\hline
\end{tabular}

$* \mathrm{P}<0.05$

The research data show that the boys who are judged as obesity compared with those whose body fat ration is normal, the muscle of the parts of the body differs a little but the fat accumulates on the lower limb and the trunk and the explosive force of the lower limb has the significant difference. We analyze it from the point of mechanical. One aspect is that when the standing long jump happens, the force produced by the shrinkage of muscle needs to overcome the gravity and do work, but the increase of body fat makes the increase of man qualities so when we want to change the motion state, it need more strength. Another aspect is the fat can't produce the force by shrinkage itself and it will produce friction when the muscle shrinks, so it will consume the power instead, and it will reduce the shrink efficiency of the muscle. And when the body fat content is more, it will consume more power, we can notice that the fat has a negative effect on the power of the lower limb in the motion of standing long jump in which the body fat overcomes the weight.

The boys who are obese differ a little from the boys whose body fat ration is normal in terms of the result of the push-ups because they differ a little in the trunk muscle's content. The girls who are judged as obesity, the fat of whom concentrates on every 
part of the body, and compared with those whose body fat ration is normal, they have a significant difference in the upper and lower limbs, the body fat ration of upper limb has exceed 30\%. What's more, the girls exercise little in the ordinary life and it causes the accumulation of the fat on the upper limb, so it makes a significant difference in terms of the upper and lower limbs of the obese girls. Therefore, on the condition that the muscle content is almost same, the direct reason for the strength quality of every part of the physical is the accumulation of the partial fat.

\section{CONCLUSIONS AND SUGGESTIONS}

\subsection{Conclusions}

1. The significant differences in the body composition between female and male college students include that the muscle content of girls is greatly less than boys but the body fat content of girls is higher, and that obese boys' fat accumulates in the lower limbs and abdomen but girls' is also in the upper limbs except the above part.

2. The body fat rate has bad effects on the strength of boys' muscle in lower limbs but is negative to the strength of the upper and lower limbs for girls.

\subsection{Suggestions}

1. The study analyzed in the perspective of body composition found than the fat of research objects mainly accumulates in the lower limbs and abdomen. The fat goes into the blood in the form of free fatty acid and then goes into the liver and other parts of the body along with the blood. Low density lipoprotein is one of the dangerous factors to suffer from cardiocerebrovascular diseases, so we should evaluate the obesity accurately, strengthen the awareness against obesity and increase students' scientific understanding of health.

2. In physical education and physical exercise after school, college students should mainly take aerobic exercises aiming at providing full exercise to each of body functions, and female students should take some exercises targeting to increase the strength of the upper and lower limbs.

\section{ACKNOWLEDGEMENT}

This work is supported by the Fundamental Research Funds for the Central Universities (Grant No. DUT14RW105) and Education and Teaching Reform Funds of Dalian University of Technology (Grant No. MS2014068).

\section{REFERENCES}

[1] Billat, V.L. \& Lapretre P.M. \& Heubert, R.P.et al. 2003. Influenceof Acute Moderate Hypoxia an Time to Exhaustion at VO2max in Un acclim at ized Run ners. Int J S ports Med24( 1) : 9-14.

[2] Chen, Anhuai. \& Chen, Yinsheng. 2000. Dictionary of Sports. Shanghai: Shanghai Lexicographical Publishing House.

[3] Han, Zhaihong. \& Wang, Mingxiao. 2006. High Blood Pressure with Overweight and Obesity. Chinese research journal of cardiovascular disease (10): 738- 739.

[4] Li, Zonghao. 2002. Science of Sports Training. Higher Education Press.

[5] Lukaski, H.C. 1985.Assessment of fat mass using bioleetric impedance measurements of the human body. Am J Clin Nutr, 4:1810.

[6] Morton, R.H. \& Billat, V. 2000. Maxim al E ndurance Time at VO2max. Med S ci Sports Exe 32(8): 1496-1504.

[7] Neovius, M. \& Hemmingsson, E. \& Freyschuss. et al. 2006. Bioeleetr iealimPedance underestimates total and truneal fatness in abdominally obese women. Obesity (SilverSPring) 14(10): 1731-8.

[8] Oguri Yoshito. \& Hada Michinobu. \& Mitsunaga tsutomu. 2001. Obesity hidden in University students. Journal of Fujita Academic Institute of Medicine 25, 8183.

[9] Schwarz, Steven. 2007. Obesity. Emedicine.

[10] Wang, Ruiyuan. \& Liu, Shanyun. etc. 2002. Exercise Physiology. Beijing: People's Sports Press.

[11] Zhang, Binnan. \& Guo, Junyi. \& Liu, Xiaojun. 2009. The Experiment Research of Aerobic Exercise Intervention Plans to Improve Female College Students Physique. Journal of Beijing University of Physical Education. 32(4): $72-74$.

[12] Zhang, Haiping. 2003. Related Research on Muscle Morphological Characteristics and Muscle Strength. Journal of Shenyang Sports Institute(1):44-46. 